November) and in Norway (where there is a vote two weeks later). If the Finnish vote (53:47 in favour of membership) had been more decisively in favour of membership, the effects elsewhere in Scandinavia would have been greater, but they are likely still to be positive. So the weekend's business in Finland is to be welcomed. What does that imply for the future of the EU, and for Europe as a whole?

That more means better is true in many respects. Because international trade is not a zero-sum game but a means by which Adam Smith's beneficent division of labour may be extended internationally, the EU as a single market will be strengthened to the benefit of all, or almost all. But supporters of the European enterprise insist that there is more to it than that. Nobody forgets that one purpose of the Treaty of Rome was to create a framework within which future European wars would be unthinkable. (The risk may have receded in the recent past, but there is still some way to go.) And then, as European statesmen are fond of saying, there is a cultural dimension that cannot be overlooked.

The trouble, sadly, is that the cultural argument conceals a difficulty. Europe is not culturally homogeneous, as can easily be told by the gedanken experiment of comparing a European journey from, say, Oslo to Naples with a journey of comparable distance from, say, Omaha (Nebraska) to Houston (Texas). By comparison with the United States, Europe is almost bewilderingly diverse in cultural respects. It is not merely that languages and school systems differ from one place to another, with the consequence that people's mobility is necessarily constrained, but that cultural diversity is part of Europe's interest and, ultimately, of its strength.

So how to preserve diversity while enlarging membership, perhaps ultimately as far as the Urals? The European Commission, often wrongly accused of homogenizing inclinations, should nevertheless be more active in this respect, if only to counter the impression created by the necessary uniformity of the directives it must repeatedly issue. But greater subsidies for itinerant folk-dancers will not suffice. The commission should instead concentrate on more efficient ways of teaching second and third languages to young people and on strengthening those parts of European culture where diversity can coexist happily with uniformity. Higher education and research are the obvious places at which to start (and the commission's existing schemes for making students and research fellows more mobile are a good beginning). But there is much more yet to be done.

The most urgent need is for a catalogue and then an understanding of Europe's system of higher education. Especially with the general drive for increased participation in higher education, national systems are steadily becoming more diverse. But they already differ from each other in quite radical ways; sometimes, major universities are managed centrally (Italy and France), sometimes regionally (Germany) and sometimes are supposedly autonomous, but centrally financed (Britain). Some employ academics from elsewhere on equal terms, others do not. Arrangements for the support of research differ from one country or even university to another. Links between universities and public research institutes are either strong or weak. To list these differences is not to advocate their disappearance, although Europe's interest is that academics should be as free to wander the surface of the continent as they were in the fifteenth century. For the time being, it would help if the commission merely undertook to tell its constituents how diverse is the present system, and why.

\section{Lady Luck's millennium}

Poor Britain's plans for the beginning of a new millennium will be almost literally in the lap of the gods.

SiNCE Britain decided last year on the creation of a national lottery, the government has been rubbing its hands with delight at the prospect of a cornucopia of off-budget income that can be spent on good causes for which the political case is only marginal - overseas aid charities, the domestic voluntary sector, the arts in general and the celebration of the millennium. On the face of things, the expectation is correct. The market-men have a naturally beguiling message: the puritanical can be tempted to buy lottery tickets on the grounds that they will be supporting good causes, the greedy by the promise of becoming millionaires.

The celebration of the millennium, financed by a fifth of the proceeds from the lottery (estimated to amount to $£ 1.6$ billion by 2000), is meant to take the form of the creation of "additional landmarks of very high quality". The government has appointed a Millennium Commission, with two members of the cabinet among its eight members, which in turn had appointed a chief executive, Mr Nicholas Hinton, to administer its funds. Hinton has a distinguished record as a charity administrator, most recently as director of the Save the Children Fund, going back over three decades. Then, last week, seven days before Hinton was due to start full-time in his new job, he was told that his services would not now be required. He has been compensated with three months' pay.

This is a curious way to carry on, to say the least of it. The nub of the disagreement is the commission's fear that Hinton would assume an unwelcome influence in the selection of projects qualifying for support. What this appears to mean is that Hinton would exclude the most wild and woolly proposals from formal consideration by the commission, and that he would also keep a zealous eye on the spending of the commission's funds. The commission's members appear to yearn for more direct involvement, which is their privilege.

The trouble is that the members are all part-timers, mostly with other demanding jobs. Worse, in the nature of the British government's way of dealing with ministers, its two placemen on the commission (Mr Stephen Dorrell and Mr Michael Heseltine) will have long since departed their jobs before the millennium is upon us, and so will not be called to account for how the money is spent. Worse still, the scale on which British people invest in lottery tickets has yet to be determined, but may be much smaller than the marketing consortium called Camelot expects. At this rate, the commission will soon be pleading for a postponement of the millennium. 